\title{
Copper-Oximes: The Story Continues
}

\author{
Alguacil FJ* \\ Centro Nacional de Investigaciones Metalurgicas (CSIC), Spain
}

\section{Opinion}

More than 50 years ago, a relationship between a metal, copper, and a type of chemicals,

ISSN: 2578-0255

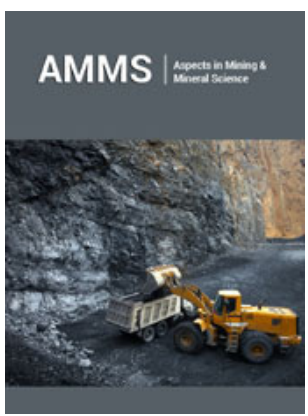

*Corresponding author: F J Alguacil, Centro Nacional de Investigaciones Metalurgicas (CSIC), Avda Gregorio del Amo 8, Spain

Submission: 監 August 07, 2019

Published: 毕September 06, 2019

Volume 3 - Issue 3

How to cite this article: Alguacil FJ. Copper-Oximes: The Story Continues. Aspects Min Miner Sci.3(3). AMMS.000566.2019. DOI: 10.31031/AMMS.2019.03.000566

Copyright@ Alguacil FJ, This article is distributed under the terms of the Creative Commons Attribution 4.0 International License, which permits unrestricted use and redistribution provided that the original author and source are credited. oximes, began. This was caused by the copper industry, which needed of a process which fulfilled the requirements for a process allowing the treatment of copper oxidized ores, unsuitable for their treatment by means of pyrometallurgical processing. The process was, and it is, a sequence of steps, as shown in Figure 1. In resume, by means of three sequential steps: leaching-solvent extraction-electrowinning, copper cathode is produced from low grade oxidized copper ores. The process success was that the exiting solution of one step fed the next step, and the exiting solution from the step fed the previous one. That is, a near perfect closed process. In the middle of the process, the solvent extraction step, or liquidliquid extraction step in nowadays more correct environmental language, was the key of this successful industrial process. And, in this step, a type of chemicals, oximes, and specially $\beta$-hydroxy oximes (Figure 2), contributed at a maximum to the success. $\beta$-hydroxy oximes were not strange in the Chemical world, since they were Analytical Chemistry long used reactive, but this new industrial use boosted their knowledge to the mining industry. This was because $\beta$-hydroxy oximes form, in a very reasonable short time (no more than $10 \mathrm{~min}$ of reaction), a stable chelate compound with $\mathrm{Cu}^{2+}$, allowing the separation of this metal from common impurities found in the leaching solutions, specially $\mathrm{Fe}^{3+}$. The reaction responsible for the above was:

$$
C u_{a q}^{2+}+2 H R_{o r g} \Leftrightarrow C u R_{2_{o r g}}+2 H_{a q}^{2+}
$$

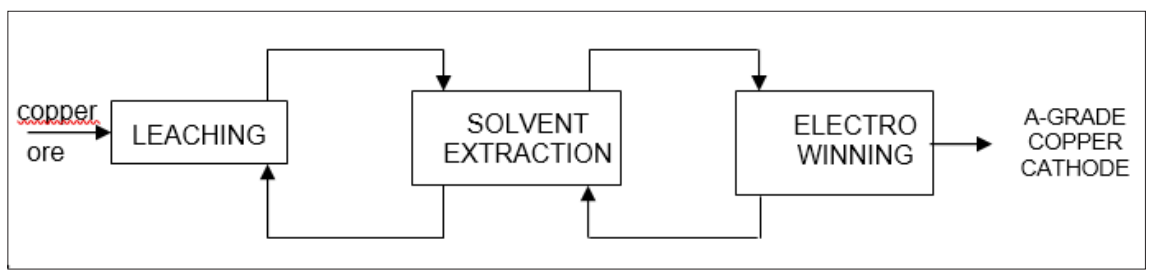

Figure 1: The scheme for copper recovery from copper oxidized ores by the sequence leaching-solvent extraction-electrowinning.

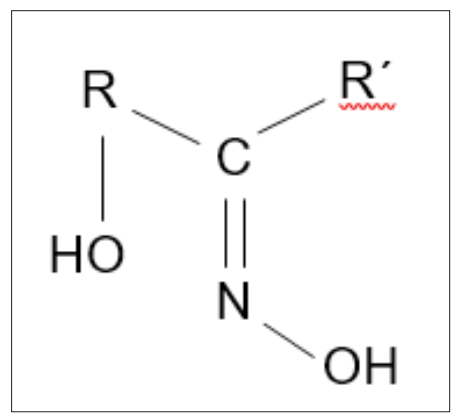

Figure 2: General structure of $\beta$-hydroxyoximes. $R$ is alkyl or aryl groups. $\mathrm{R}^{\prime}=\mathrm{CH}_{3}$ (ketoximes). $\mathrm{R}^{\prime}=\mathrm{H}$ (salycilaldoximes). The hydroxyl group linked to $\mathrm{R}$ are the responsible for the cation exchange, whereas the nitrogen atom is the responsible for the formation of the chelate compound by donation of an electron pair to the $\mathrm{Cu}^{2}+$ atom. In practice, $\beta$-hydroxyoximes were dissolved in kerosene-type diluents. 
where aq, stands for the aqueous solution exiting the leaching step (rich in $\mathrm{Cu}^{2+}$ ), and to the aqueous solution exiting the solvent extraction step and feeding the leaching step (with a high $\mathrm{H}^{+}$ concentration). $\mathrm{HR}$ and $\mathrm{CuR}_{2}$ represented the $\beta$-hydroxy oxime and the $\mathrm{Cu}^{2+}-\beta$-hydroxy oxime compounds in the organic phase, respectively. The reaction also exchanged cations; $\mathrm{Cu}^{2+}$ and $\mathrm{H}^{+}$, for this reason the reaction was not strictly just about the formation of a chelate compound but also about a cation exchange reaction. After extraction, the solvent extraction process had a second important step called stripping, which in copper terms was the reversal of eq.(1), that is, the organic phase containing copper was put into contact with an acidic solution exiting the electrowinning operation, releasing copper(II) to a new acidic aqueous solution which fed the electrowinning step and the extractant was regenerated to fed another copper-extraction step. As it was said before, an ideal closed circuit to render A-grade copper cathode.

The first $\beta$-hydroxy oxime to be accepted commercially for copper solvent extraction, about 1963, was called LIX 63 and was manufactured by Genera Mills Inc.(now Basf), actually the industrial operation operated either with salicylaldoximes, ketoximes or tailored mixtures of both types, with Western manufactures apparently reduced to Basf (LIX type reagents) and Solvay (Acorga type reagents). The first operational plant, using the leaching- solvent extraction-electrowinning concept, was the Ranchers Bluebird Nine in Arizona, which entered in production around 1968, from then, the number of worldwide plants was continuously growing; all together expecting to reach near $20 \%$ of the total estimated copper production of almost 26 Mton by 2020. The main copper (pyro and hydrometallurgical processing) producers are: Chile (by far the largest producer), Peru, China, USA and Democratic Republic of the Congo, of the total copper-producers countries of around 21 Mton by 2018. The scheme shown in Figure 1 was also adapted to the treatment of leachates from certain copper sulfide ores, copper scraps and copper-bearing hazardous materials such as copper flue dusts (generated in the copper pyrometallurgical production). Besides its industrial applications, the whole scheme of Figure 1, or each of the unit separations considered separately, had attracted the attention of academia and researchers, which along the years had published and generated a myriad of scientific publications and patents. Fortunately, this interest is not stopped today, since new or largely unresolved problems still are around, i.e. the problematic of the presence of chloride ions in the solvent extraction-electrowinning circuit, oximes degradation, etc.

Entering the third decade of the XXI century, it can be concluded that the copper-oximes story still continues. 